\title{
EFFECTS OF HYPOPHYSECTOMY AND DEXAMETHASONE ADMINISTRATION ON CENTRAL AND PERIPHERAL S-ADENOSYLMETHIONINE LEVELS ${ }^{1}$
}

\author{
DONA L. WONG, ${ }^{* 2}$ ERIC L. ZAGER, AND ROLAND D. CIARANELLO \\ * Laboratory of Developmental Neurochemistry, Division of Child Psychiatry and Child Development, Department of \\ Psychiatry and Behavioral Sciences, Stanford University School of Medicine, Stanford, California 94305
}

Received October 7, 1981; Revised December 21, 1981; Accepted December 30, 1981

\begin{abstract}
The effects of hypophysectomy and dexamethasone administration on $S$-adenosylmethionine (SAM) levels in the adrenal, liver, pineal, and various brain regions were examined to determine the central and peripheral relationships between SAM and glucocorticoids in vivo. A simple and sensitive radioenzymatic assay was developed to measure tissue SAM concentrations following removal of its demethylated metabolite, $S$-adenosylhomocysteine (SAH), whose presence precludes accurate SAM determinations.

Three patterns of SAM control emerged. In the adrenal, pineal, striatum, and midbrain, SAM levels fell after hypophysectomy and were restored by dexamethasone administration. In the thalamus, hypothalamus, hippocampus, and cerebellum, SAM levels increased after hypophysectomy and were not altered further by dexamethasone administration. In the liver, cortex, septum, and pons-medulla, SAM levels were not affected by either hypophysectomy or dexamethasone administration.

These results suggest that multiple controls regulate SAM levels in vivo. The control factors are both highly tissue and region specific. While glucocorticoids are an important regulatory factor of SAM in some peripheral and CNS tissues, they are not the sole regulatory factor. In CNS regions where hypophysectomy increases SAM levels but glucocorticoid administration does not reverse the effects, other hypothalamic hormones, pituitary hormones, or neural factors may be involved in SAM regulation. Likewise, in regions where neither hypophysectomy nor glucocorticoid administration affects SAM levels, hypothalamic or neural factors may be involved even though pituitary factors do not appear to be important.
\end{abstract}

$S$-Adenosylmethionine (SAM) serves as the methyl donor in a variety of enzymatic transmethylation reactions. While studying the regulation of adrenal medullary phenylethanolamine $N$-methyltransferase (PNMT), the terminal enzyme in adrenaline biosynthesis, we observed that SAM protected this catecholamine biosynthetic enzyme against in vitro proteolysis by trypsin. SAM appears to protect PNMT by binding to the methyltransferase and altering its tertiary conformation so that it is less susceptible to proteolytic attack (Berenbeim et al., 1979). Since glucocorticoids control in vivo steady state levels of this enzyme by inhibiting proteolytic degrada-

\footnotetext{
' This work was supported by National Science Foundation Grants PCM 78-14183 and PCM 80-11525 and National Institute of Mental Health Grant MH 25998. R. D. C. is the recipient of Research Caree Development Award MH 00219 from the National Institute of Mental Health.

${ }^{2}$ To whom correspondence should be addressed.
}

tion (Ciaranello and Black, 1971; Moore and Phillipson, 1975; Ciaranello, 1978), we proposed that SAM acts as an intracellular regulatory agent, whose levels are controlled by glucocorticoids.

Another biogenic amine enzyme, hydroxyindole $O$-methyltransferase (HIOMT), the pineal enzyme involved in melatonin synthesis, is regulated in a similar fashion by glucocorticoids. HIOMT levels fall after hypophysectomy and can be restored by the administration of adrenocorticotropic hormone (ACTH), dexamethasone, or SAM. SAM modulates the in vitro degradation of HIOMT as well as PNMT (Sandrock et al., 1980). Therefore, glucocorticoids may regulate SAM levels in both the adrenal and pineal, the tissues in which PNMT and HIOMT are primarily located.

It became of interest to define further the role of SAM in the in vivo regulation of PNMT and HIOMT degradation and in the regulation of other biological systems in the CNS and periphery. To accomplish this, we first 
developed a simple, sensitive assay for SAM which distinguishes between SAM and its demethylated metabolite, $S$-adenosylhomocysteine (SAH). SAH is a potent inhibitor of most methyltransferases (Deguchi and Barchas, 1971). Since most SAM radioenzymatic assays utilize methyltransferases (Baldessarini and Kopin, 1966; $\mathrm{Yu}, 1978$ ), it is essential to separate SAM from SAH. This rapid, inexpensive, single label radioenzymatic assay was utilized in the studies on the hormonal control of SAM levels in various tissues described in this report. In some lissues and brain regions, glucocorticoids appear to be essential for the maintenance of steady state SAM levels. In others, however, separate endocrine or neuronal mechanisms may be operant. These findings suggest that SAM levels in the body are controlled by multiple factors, that endocrine influences are important, but not exclusive, regulatory factors in modulating SAM levels, and that the control of SAM is more complex than previously suspected.

\section{Materials and Methods}

Preparation of Dowex $1-X 8$ anion exchange resin. SAM and SAH were separated on a Dowex 1-X8, 200 to 400 mesh, $\mathrm{HCO}_{3}^{-}$column (Bio-Rad, Richmond, CA) by a modification of the method of Shapiro and Ehninger (1966). The resin was pre-washed extensively with $1 \mathrm{M}$ hydrochloric acid and $1 \mathrm{M}$ sodium hydroxide. The resin then was equilibrated and stored in $1 \mathbf{M ~ N a H C O}$. Columns of $0.5 \mathrm{~cm}^{3}$ bed volume were prepared in a glass microcolumn, $0.7 \mathrm{~cm}$ in diameter (Radnoti, Monrovia, CA), fitted with a sintered glass disk and a two-way microvalve with a drain tip. Immediately before sample application, the column was re-equilibrated with $25 \mathrm{ml}$ of $1 \mathrm{M} \mathrm{NaHCO}$, followed by $50 \mathrm{ml}$ of distilled water.

Preparation of hydroxyindole O-methyltransferase. Hydroxyindole $O$-methyltransferase (HIOMT) was prepared by a modification of the procedure of Jackson and Lovenberg (1971). Frozen beef pineals were homogenized in $50 \mathrm{~mm}$ Tris-HCl, pH 7.4, $0.5 \mathrm{~mm}$ dithiothreitol (DTT) $(7.6 \mathrm{gm} / 38 \mathrm{ml})$ using a motor-driven glass homogenizer. The extract was centrifuged at $37,000 \times \mathrm{g}$ for $30 \mathrm{~min}$ at $0^{\circ} \mathrm{C}$. The supernatant was adjusted to $37 \%$ saturation with solid ammonium sulfate at $0^{\circ} \mathrm{C}$. After equilibration for $15 \mathrm{~min}$, the solution was centrifuged at $10,000 \times \mathrm{g}$ for 20 min. The supernatant was readjusted to $65 \%$ saturation with ammonium sulfate, and the equilibration and centrifugation steps were repeated. The pellet was resuspended in 50 Inм Tris-HCl, pH 7.4, 0.5 Inм DTT and dialyzed overnight in the cold against the same buffer. The purified enzyme was stored at $-70^{\circ} \mathrm{C}$ until use. Under these conditions, the purified enzyme was stable for about 2 months.

Preparation of tissue. All experiments were performed on male Sprague-Dawley rats (160 to $200 \mathrm{gm}$ ) obtained from Zivic Miller (Allison Park, PA). Surgical operations were performed by the supplier. Hypophysectomized animals were maintained on $1 / 4$ normal plasma salts for the duration of the experiment. Following acclimation to housing conditions for 1 week, dexamethasone was administered as described in the table and figure legends. The quality administered per injection and the number of injections were determined by dose-response curves optimizing increases in PNMT and HIOMT activity.
Rats were killed by cervical dislocation. When measuring adrenal SAM levels, the glands were removed, homogenized in $0.25 \mathrm{ml}$ of $10 \%$ trichloroacetic acid (TCA) in $0.05 \mathrm{M}$ hydrochloric acid, and centrifuged at $3,000 \times \mathrm{g}$ for $30 \mathrm{~min}$ at $0^{\circ} \mathrm{C}$. The supernatant was washed three times with $0.5 \mathrm{ml}$ of ether saturated with $0.05 \mathrm{M} \mathrm{HCl}$. Residual ether was evaporated under a gentle stream of nitrogen gas at 0 to $4^{\circ} \mathrm{C}$, and samples were stored overnight at $4^{\circ} \mathrm{C}$. All other tissues were homogenized in 5 vol of TCA-HCl. The remaining steps were identical to those used for adrenals with appropriate adjustments for volume differences. Blanks were prepared identically in the absence of tissue.

Immediately before application to the column, a 0.2 $\mathrm{ml}$ aliquot of tissue extract was diluted to $1.0 \mathrm{ml}$ with distilled water. Five microliters of $\left[{ }^{3} \mathrm{H}\right] \mathrm{SAM}$ (Amersham/ Searle, Arlington Heights, IL; specific activity adjusted to $30 \mathrm{mCi} / \mathrm{mmol}$ ) was added. Fifty microliters of the diluted sample was set aside for the determination of SAM recoveries. The sample then was applied to the column. The initial $0.5 \mathrm{ml}$ of effluent was discarded, and the subsequent effluent was collected. The column then was washed with $10 \mathrm{ml}$ of distilled water. The first $1.5 \mathrm{ml}$ of wash was collected and combined with the sample effluent. One milliliter of the combined column material was assayed for SAM content as described below. Fifty microliters of the same was counted for radioactive SAM. Recovery was estimated by comparing the counts recovered from the column with those applied. All radioactive samples were counted in $10 \mathrm{ml}$ of Betaphase liquid scintillant (Westchem, San Diego).

Assay for SAM. SAM was measured using a modification of the procedure of Baldessarini and Kopin (1966); the most significant modifications were the column step separating SAM and SAH and the use of a single radioisotopic label. The assay was a radioenzymatic isotope dilution procedure in which the presence of unlabeled SAM reduced the formation of radioactive melatonin. A standard curve was established for each set of unknown tissues using unlabeled SAM purified by a modification of the method of Deguchi and Barchas (1971). Standards of $0.4,0.8,1.2,1.6$, and $2.0 \mathrm{nmol}$ of SAM were prepared in duplicate in $1.0 \mathrm{ml}$ of distilled water. To standards and tissue samples were added $25 \mu \mathrm{l}$ of $\left[{ }^{3} \mathrm{H}\right] \mathrm{SAM}$, (specific activity adjusted to $540 \mathrm{mCi} / \mathrm{mmol}$ ) and $10 \mu l$ of $50 \mathrm{~mm}$ DTT in $50 \mathrm{~mm}$ Tris- $\mathrm{HCl}, \mathrm{pH} 7.4$. The reaction was begun by the addition of a solution containing $9.0 \mathrm{mmol}$ of Tris-

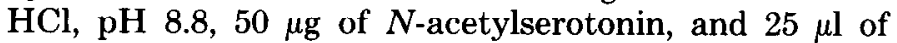
hydroxyindole $O$-methyltransferase (specific activity, $0.23 \mathrm{unit} / \mathrm{ml}$ ) in a final volume of $200 \mu \mathrm{l}$. After incubation for $20 \mathrm{~min}$ at $37^{\circ} \mathrm{C}$, the reaction was terminated by the addition of $0.5 \mathrm{ml}$ of $0.5 \mathrm{M}$ sodium borate, $\mathrm{pH} 10$. $\left[{ }^{3} \mathrm{H}\right]$ Melatonin was extracted into $5 \mathrm{ml}$ of $(97: 3)$ toluene:isoamyl alcohol; $3 \mathrm{ml}$ of the organic phase was counted in $10 \mathrm{ml}$ of Betamax (Westchem, San Diego). The standard curve was generated by linear regression analysis of duplicate data points (Fig. 2). The SAM content in each sample then was determined from the standard curve.

Statistical methods. To determine the SAM tissue concentrations, a SAM standard curve was generated for each experiment. Duplicate data points were analyzed by linear regression analysis, yielding a linear equation of 
the form

$$
y=m x+b
$$

where $m$ is the slope of the standard curve, $b$ is the $y$ intercept, $y$ is the amount of radioactive product formed in the enzymatic reaction utilizing the sample, and $x$ is the quantity of SAM associated with that amount of radioactive product.

Replicates were run for each tissue or each group of tissue. The means and SEM were determined from this data. The significance between treatment groups was evaluated using two-tailed $t$ statistics.

\section{Results}

Separation of $S A M$ and $S A H$ by anion exchange chromatography. Figure 1 shows the elution profile for the separation of SAM and SAH on the Dowex anion exchange resin. A single peak emerges. Examination of this peak by thin layer chromatography in 1butanol:acetic acid:water (25:50:25) indicated only the presence of SAM. When a pure sample of SAH, well in excess of tissue concentrations (Salvatore et al., 1971), was applied to the column, no $A_{254}$ absorbing material eluted. Thus, SAM and SAH are separated completely by anion exchange chromatography on Dowex 1-X8 as previously reported (Shapiro and Ehninger, 1966).

Figure 1 also shows that the peaks for $\left[{ }^{3} \mathbf{H}\right] \mathrm{SAM}$, sample SAM as measured by absorption at $254 \mathrm{~nm}$, and

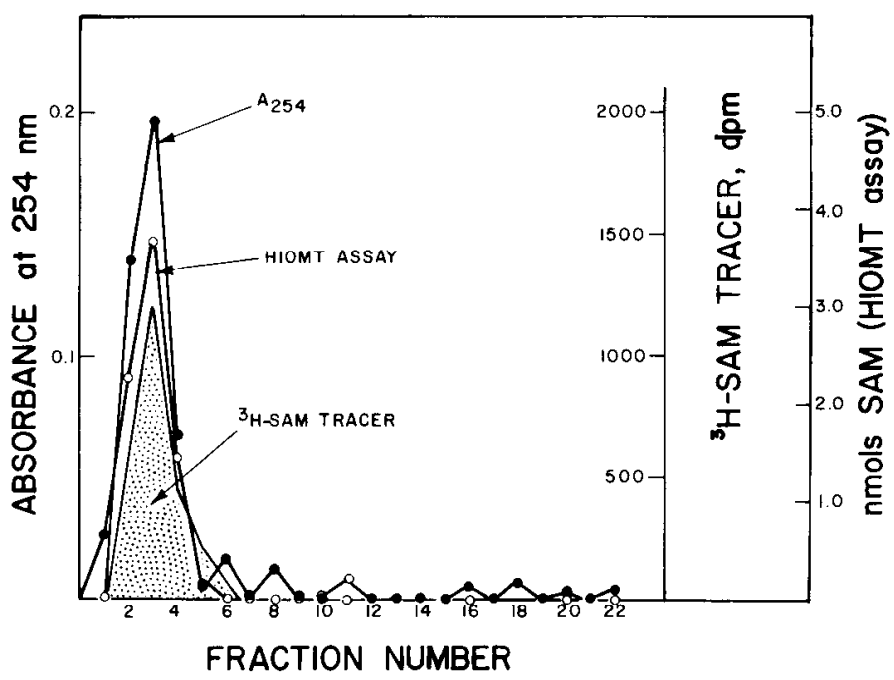

Figure 1. Separation of SAM and SAH on Dowex 1-X8, 200 to 400 mesh, $1 \mathrm{M} \mathrm{NaHCO}$. To a $1-\mathrm{ml}$ sample, containing 12.1 nmol of SAM and $12.0 \mathrm{nmol}$ of $\mathrm{SAH}$, was added $10 \mu \mathrm{l}$ of $\left[{ }^{3} \mathrm{H}\right] \mathrm{SAM}$ (specific activity, $15 \mathrm{mCi} / \mathrm{mmol}$ ). A $0.5-\mathrm{cm}^{3}$ column of Dowex 1-X8 (200 to 400 mesh, 1 M NaHCO${ }_{3}$ ) was washed with $25 \mathrm{ml}$ of freshly prepared $1 \mathrm{M} \mathrm{NaHCO}$, followed by $50 \mathrm{ml}$ of distilled water. The sample was applied, followed by $10 \mathrm{ml}$ of distilled water, and $0.5-\mathrm{ml}$ fractions were collected. The behavior of SAM and SAH on the anion exchange resin was monitored by following the absorption at $254 \mathrm{~nm}$, the radioactivity profile, and the nanomoles of SAM as measured by the HIOMT isotope dilution assay described under "Materials and Methods." Recoveries for SAM were $87 \%, 95 \%$, and $86 \%$, respectively. Thin layer chromatography of the fractions showed that $\mathrm{SAH}$ was absent from the SAM-containing fractions, suggesting that $\mathrm{SAH}$ completely binds to the column as expected. sample SAM as measured by radioenzymatic assay are exactly coincident. No SAM emerges in the first $0.5 \mathrm{ml}$ of column effluent. The following four $0.5-\mathrm{ml}$ fractions represent the entire recoverable portion of SAM. Continued elution with distilled water results in no additional recovery of SAM.

Typical column recoveries for SAM range from 51.0 to $83.3 \%$ (Table I) and average $61.9 \pm 5.5 \%$. Recoveries are not improved by additional resin preparation or further elution and seem dependent on batch variations in the resin. The column recoveries within a given experiment are highly reproducible. Variation in recoveries most often occurs between experiments, particularly when new batches of resin are employed.

Assay for SAM. Figure 2 shows a typical standard curve used in the measurement of endogenous levels of SAM. The assay is linear in the range of 0 to $2 \mathrm{nmol}$. Once the standard curve has been constructed, unknown amounts of SAM in samples can be calculated from the amount of radioactive product formed, the $y$ intercept, and the slope of the standard curve.

The separation of SAM from SAH prior to measurement is critical since $\mathrm{SAH}$ is a very potent inhibitor of HIOMT (Deguchi and Barchas, 1971). Our studies indicate that the $K_{m}$ for SAM is $2.04 \mu \mathrm{M}$, while the $K_{i}$ for SAH is approximately 10 -fold lower, $0.22 \mu \mathrm{M}$. Thus, it is essential that SAM be measured free of SAH contamination, since traces of $\mathrm{SAH}$ will lead to high estimates of the SAM content. For example, in rat adrenal gland supernatants which have not been passed through the Dowex column, the combination of SAH and SAM gives "apparent SAM" values which are 2.6 times those measured when $\mathrm{SAH}$ has been removed from the sample.

Measurements of tissue levels of SAM. SAM levels were determined in several rat tissues. Table II summarizes the values obtained. Spleen, liver, and kidney have the highest SAM concentrations, while heart and brain (Table III) have the lowest. In general, most of the values obtained for tissue SAM are lower than published literature values (Baldessarini and Kopin, 1966; Salvatore et al., 1971; Yu, 1978), while the dispersion about the mean

\section{TABLE I}

$S$-Adenosylmethionine recovered from anion exchange columns A $0.5-\mathrm{cm}^{3}$ column of Dowex 1-X8 (200 to 400 mesh, $\mathrm{HCO}_{3}^{-}$) was equilibrated with $25 \mathrm{ml}$ of $1 \mathrm{M} \mathrm{NaHCO}$, followed by $50 \mathrm{ml}$ of distilled water. Tissue homogenates and blanks were prepared as described under "Materials and Methods." Tissue samples or samples of pure SAM were supplemented with $5 \mu \mathrm{l}$ of $\left[{ }^{3} \mathrm{H}\right] \mathrm{SAM}$ tracer (specific activity, $0.4 \mu \mathrm{Ci} / \mathrm{mmol}$ ) per $0.5 \mathrm{ml}$. One milliliter of blank was applied to the column, followed by $10 \mathrm{ml}$ of distilled water. The first $0.5 \mathrm{ml}$ was discarded. The second $2.0 \mathrm{ml}$ was collected. Columns were re-equilibrated with $\mathrm{NaHCO}_{3}$ and distilled water. The sample was applied and treated in the same fashion as the blank. A $0.1-\mathrm{ml}$ aliquot of the $2.0-\mathrm{ml}$ blank and tissue sample fraction was counted in $10 \mathrm{ml}$ of Betaphase for recovery measurements.

\begin{tabular}{lcc}
\hline \multicolumn{1}{c}{ Tissue } & $n$ & Percent Recovery \\
\hline Liver & 24 & $54.8 \pm 1.7$ \\
Striata & 36 & $52.8 \pm 0.9$ \\
Adrenals & 28 & $67.7 \pm 2.3$ \\
Cerebellum & 35 & $51.0 \pm 1.0$ \\
Pineal & 29 & $83.3 \pm 2.1$ \\
\hline
\end{tabular}




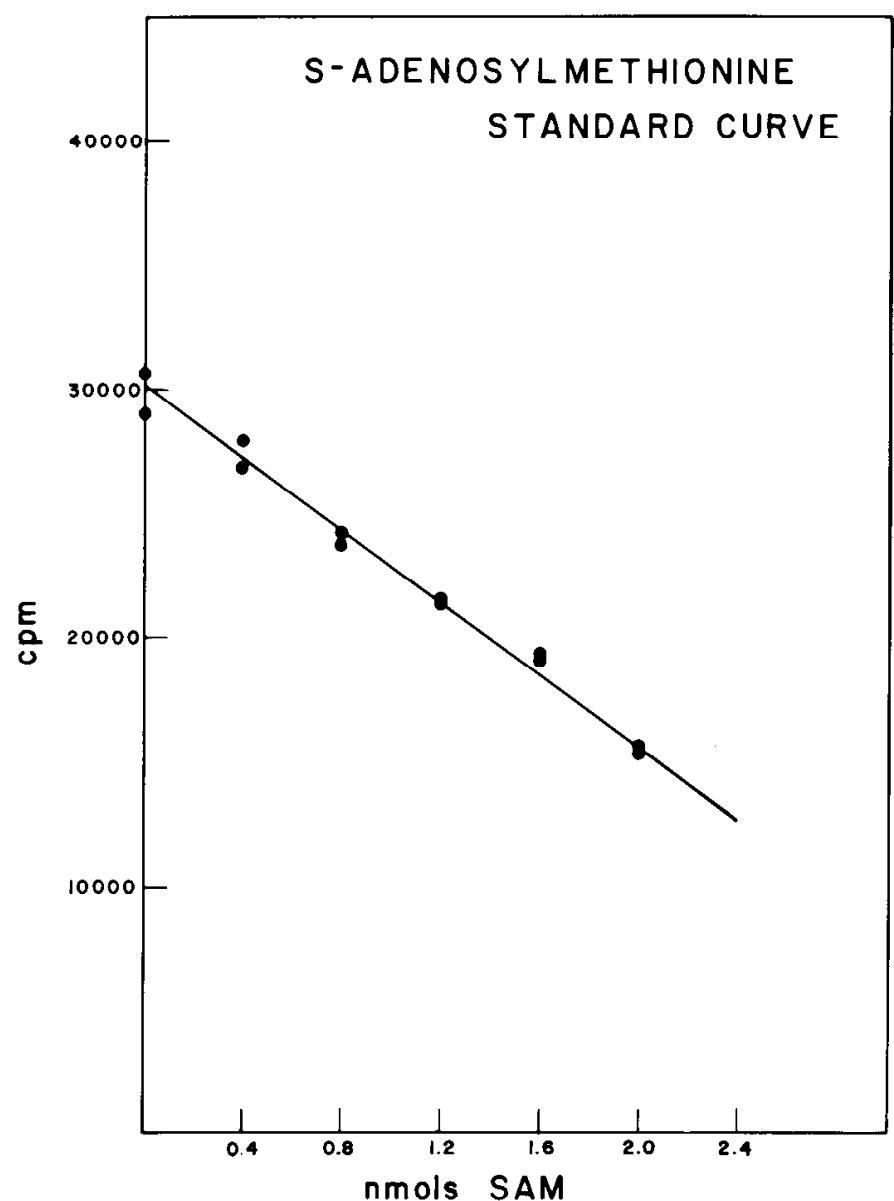

Figure 2. Standard curve for the measurement of $S$-adenosylmethionine. Duplicate samples containing $0,0.4,0.8,1.2,1.6$, and $2.0 \mathrm{nmol}$ of unlabeled SAM were prepared and assayed for HIOMT activity as previously described. Linear regression analysis of the data points produces a curve from which tissue SAM concentrations can be calculated using the $y$ intercept and the slope of the line.

is less than or equivalent to that encountered by other assay methods.

Measurement of SAM in rat brain. Analysis of SAM levels in several brain regions was conducled (Table III). Septum, cerebral cortex, and striatum had the highest SAM values, although these regions would be considered low in comparison to the values observed in peripheral tissues. Thalamus, pons-medulla, and hypothalamus were the brain regions with the lowest SAM content.

Effects of hypophysectomy on SAM levels. Our initial interest in studying the control of SAM levels was prompted by the possible role of this compound as a regulator of in vivo methyltransferase levels. We have shown previously that hypophysectomy decreases PNMT activity in rats to half the values observed in control animals and nearly abolishes pineal HIOMT activity. Although administration of ACTH or glucocorticoids does not elevate enzyme activity above normal values in control animals, these compounds do restore the activity of both enzymes toward control levels in hypophysectomized animals (Ciaranello, 1978; Sandrock et al., 1980). SAM administration to hypophysectomized rats also restores the levels of the two enzymes and stabilizes both against enzymatic degradation as well. These findings led us to propose a model in which SAM binds directly to the methyltransferases and stabilizes them against intracellular degradation (Ciaranello, 1978; Masover et al., 1979). A necessary condition of this model is that SAM must be under glucocorticoid control at least in the pineal and adrenal. In the adrenal, SAM levels fall dramatically after hypophysectomy and are partially restored by dexamethasone or ACTH administration

\section{TABLE II}

Concentration of S-adenosylmethionine in rat tissue

A $0.5-\mathrm{cm}^{3}$ column of Dowex 1-X8 (200 to 400 mesh, $\mathrm{HCO}_{3}^{-}$) was equilibrated with $1 \mathrm{M} \mathrm{NaHCO}$, followed by distilled water. Male Sprague-Dawley rats ( 160 to $200 \mathrm{gm}$ ) were killed by cervical dislocation and the various organs were removed. Tissue samples were homogenized in $5 \mathrm{vol}$ of $10 \%$ trichloroacetic acid, $0.05 \mathrm{~m}$ hydrochloric acid and centrifuged at $3000 \mathrm{rpm}$ for $30 \mathrm{~min}$ at $4^{\circ} \mathrm{C}$. Blanks of TCA-HCl and tissue samples were washed three times with twice their volume of ether saturated with $0.05 \mathrm{M} \mathrm{HCl}$. Residual ether was evaporated under $\mathrm{N}_{2}$ gas at $0^{\circ} \mathrm{C}$ and stored overnight at $4^{\circ} \mathrm{C}$. A 0.200 -ml aliquot of sample and blank was diluted to $1.0 \mathrm{ml}$ with distilled water. To the sample was added $5 \mu \mathrm{l}$ of tracer [ ${ }^{3} \mathrm{H}$ ]SAM (specific activity, $0.4 \mu \mathrm{Ci} / \mathrm{mmol}$ ) per 0.5 $\mathrm{ml}$ of original extract. Blanks were applied to the columns, followed by $10 \mathrm{ml}$ of distilled water. The first $0.5 \mathrm{ml}$ of effluent was discarded and the second $2.5 \mathrm{ml}$ was collected. The column was re-equilibrated with $\mathrm{NaHCO}_{3}$ and distilled water. Samples were run similarly to blanks. A 1.000-ml aliquot was assayed for HIOMT activity. SAM content was calculated from the $y$ intercept and the slope of the SAM standard curve. Samples were run in triplicate and standard curves generated with each experiment.

\begin{tabular}{lr}
\hline \multicolumn{1}{c}{ Tissue } & $\mu \mathrm{g} / \mathrm{gm}$ \\
\hline Spleen & $30.1 \pm 3.0$ \\
Liver & $24.9 \pm 2.3$ \\
Kidney & $21.3 \pm 1.7$ \\
Adrenals & $16.1 \pm 1.7$ \\
Lung & $14.7 \pm 1.6$ \\
Heart & $7.7 \pm 2.6$ \\
\hline
\end{tabular}

\section{TABLE III}

Regional brain distribution of S-adenosylmethionine in rats

Twelve animals were used per group. Animals were sacrificed by cervical dislocation and pineals and brains were removed. The brain was dissected regionally on ice, and tissue samples were frozen until assay. Each part was weighed prior to homogenization in $4 \mathrm{vol}$ of distilled water. To each aqueous homogenate was added 1 vol of $50 \%$ TCA, $0.25 \mathrm{M} \mathrm{HCl}$. Following mixing, samples were centrifuged and the supernatants were washed three times with twice their volume of ether saturated with $0.05 \mathrm{M} \mathrm{HCl}$. Residual ether was evaporated with a gentle stream of nitrogen gas, and samples were stored at 0 to $4^{\circ} \mathrm{C}$ overnight. SAM was measured as described under "Materials and Methods."

\begin{tabular}{lcr}
\multicolumn{1}{c}{ Brain Region } & Weight & $\mu \mathrm{g} / \mathrm{gm}$ \\
\hline & $m g$ & \\
Pineal & $-{ }^{a}$ & $0.12 \pm 0.04$ \\
Striatum & $125.4 \pm 3.0$ & $7.32 \pm 0.83$ \\
Hypothalamus & $28.0 \pm 1.6$ & $1.67 \pm 0.37$ \\
Cortex & $731.6 \pm 11.4$ & $7.39 \pm 0.25$ \\
Cerebellum & $273.8 \pm 3.8$ & $2.89 \pm 0.36$ \\
Thalamus & $174.7 \pm 6.5$ & $1.95 \pm 0.33$ \\
Hippocampus & $125.6 \pm 2.6$ & $6.01 \pm 0.40$ \\
Midbrain & $112.1 \pm 6.5$ & $4.32 \pm 0.40$ \\
Septa & $15.4 \pm 0.7$ & $12.56 \pm 0.89$ \\
Pons-medulla & $189.4 \pm 7.2$ & $1.86 \pm 0.38$
\end{tabular}

\footnotetext{
"Values for pineal are expressed in micrograms per gland.
} 
TABLE IV

$S$-Adenosylmethionine levels in adrenals from control, hypophysectomized, and dexamethasone-treated rats

Twelve animals were used per group. Animals were injected with 4 $\mathrm{mg} / \mathrm{kg}$ of dexamethasone phosphate (i.p.) daily for 1 week. Adrenals were removed and homogenized in $200 \mu \mathrm{l}$ of distilled water. A $5-\mu l$ aliquot was assayed for PNMT activity. To the remaining homogenate was added $50 \mu \mathrm{l}$ of $50 \% \mathrm{TCA}, 0.25 \mathrm{M} \mathrm{HCl}$. The sample was centrifuged for $1.5 \mathrm{~min}$ and the resulting supernatant was washed three times with twice its volume of ether saturated with $0.05 \mathrm{M} \mathrm{HCl}$. Residual ether was removed with $\mathrm{N}_{2}$ gas and the sample was stored overnight at 0 to $4^{\circ} \mathrm{C}$. SAM content was measured as described under "Materials and Methods."

\begin{tabular}{lcc}
\hline & PNMT Activity & SAM \\
\hline & units $/$ pair & $\mu g /$ pair \\
Control & $1.60 \pm 0.01$ & $0.49 \pm 0.08$ \\
Hypophysectomized & $0.45 \pm 0.01^{a}$ & $0.23 \pm 0.05^{b}$ \\
Hypophysectomized & $0.87 \pm 0.01^{c}$ & $0.60 \pm 0.09^{d}$ \\
+ dexamethasone & & \\
\hline
\end{tabular}

" $p<10^{-9}$, significant compared to control.

${ }^{b} p<0.02$, significant compared to control.

c $p<10^{-9}$, significant compared to hypophysectomized rats.

${ }^{a} p=0.12$, not significantly different from control; $p<10^{-3}$, significant compared to hypophysectomized rats.

TABLE V

HIOMT activity and SAM concentration in pineal of control, hypophysectomized, and dexamethasone-treated hypophysectomized rats

Dexamethasone-treated animals were administered the drug at a daily dosage of $4 \mathrm{mg} / \mathrm{kg}$ (i.p.) for 1 week. Animals were sacrificed and the pineals were removed. Each gland was homogenized in $250 \mu \mathrm{l}$ of distilled water. A $50-\mu l$ portion was assayed for HIOMT activity and SAM content was measured as previously described.

\begin{tabular}{lcc}
\hline & HIOMT Activity & SAM \\
\hline & units/gland & $\mu$ g/gland \\
Control & $85.3 \pm 10.4$ & $0.35 \pm 0.03$ \\
Hypophysectomized & $31.1 \pm 4.7^{a}$ & $0.15 \pm 0.01^{b}$ \\
Hypophysectomized & $51.4 \pm 6.7^{c}$ & $0.19 \pm 0.01^{d}$ \\
+ dexamethasone & &
\end{tabular}

"Significant with respect to control at $p<0.001$.

${ }^{b}$ Significant with respect to control at $p<0.0001$.

"Significant with respect to hypophysectomized rats at $p=0.03$.

"Significant with respect to hypophysectomized rats at $p=0.03$

(Table IV). Both the decline and restoration of SAM levels correspond with the changes in PNMT activity. Similar results have been obtained in the pineal (Table V). These results suggest that adrenal cortical hormones play an important role in the maintenance of SAM levels in both the adrenal and pineal.

The modulation of SAM levels by glucocorticoids in the pineal and adrenal indicates that these hormones might be an essential component in other SAM-dependent methylations. In most cases (e.g., brain phospholipid methylation), a role for glucocorticoids has not been demonstrated. The importance of glucocorticoids in maintaining SAM levels in pineal and adrenal, however, suggested that the role of glucocorticoids should be investigated in other SAM-containing tissues. Consequently, we studied SAM levels in the liver and in several brain regions.

The brain regions chosen were those which actively incorporate and bind glucocorticoids. Various regions of the brain are known to contain glucocorticoid receptors. However, the regional distribution of glucocorticoid receptors varies greatly, depending on the specific glucocorticoid radioligand used in the receptor determinations (McEwen, 1979). When $\left[{ }^{3} \mathrm{H}\right]$ corticosterone is used as the receptor-labeling ligand, the highest corticoid binding in the rat is observed in the hippocampus, septum, and amygdala, with neurons being the primary cells labeled. In contrast, $\left[{ }^{3} \mathrm{H}\right]$ dexamethasone predominantly labels glucocorticoid receptors in the hypothalamus, amygdala, septum, hippocampus, and cortex.

Figure 3 shows the results of these studies in which SAM levels were determined in brain regions of hypophysectomized rats, some of which were treated with dexamethasone. The results are quite complicated and suggest that glucocorticoids are not the sole regulators of SAM levels. Three patterns emerge from the data. In the striatum and midbrain, hypophysectomy causes a decrease in the SAM content of these tissues, while dexa-

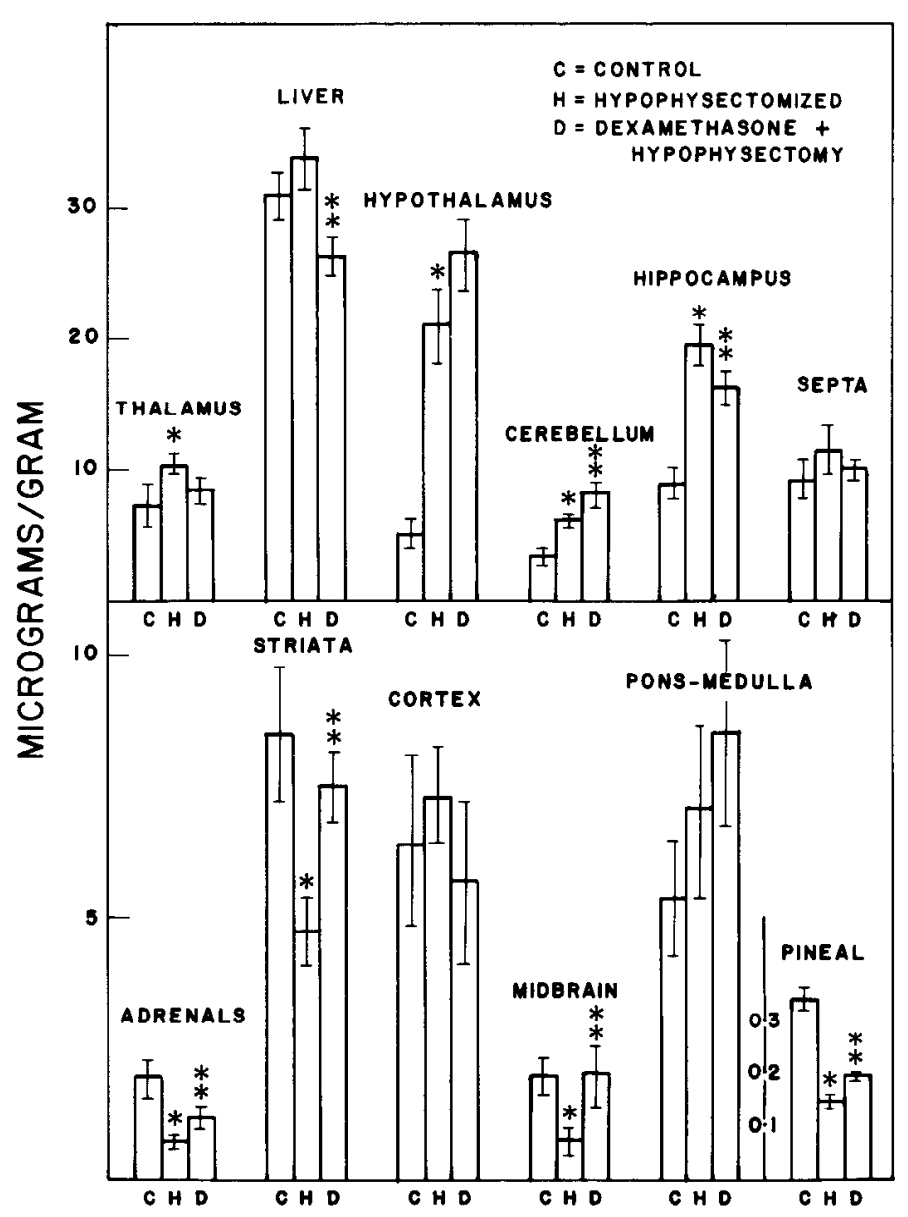

Figure 3. Regional distribution of $S$-adenosylmethionine in rat brain from control, hypophysectomized, and dexamethasone-treated animals. Each experimental group consisted of 12 animals. Dexamethasone was administered daily at a dose of 4 $\mathrm{mg} / \mathrm{kg}$ (i.p.) for 1 week. Animals were sacrificed by cervical dislocation. Brains were removed and regionally dissected. The tissue was stored frozen at $-70^{\circ} \mathrm{C}$ until use and analyzed for SAM as previously described. *, A significant difference from control; **, a significant difference from hypophysectomized animals. 
methasone administration restores the nucleoside toward control values. This is a response similar to that seen in adrenal and pineal. In contrast, hypophysectomy increases SAM levels in the thalamus, hypothalamus, hippocampus, and cerebellum, but dexamethasone administration does not alter SAM levels further. The SAM content of the cortex, septum, pons-medulla, and liver is unaffected either by hypophysectomy or dexamethasone administration.

\section{Discussion}

SAM quantitation by the procedure that we have described in this paper provides rapid and accurate measurement of this nucleoside. The values that we obtained for peripheral tissue and regional brain SAM concentrations tend to be lower than those obtained by existing methods with errors less than or comparable to the most sensitive method. These lower SAM concentrations are consistent with the complete separation of SAM from SAH. SAH is a competitive inhibitor of the methyltransferases used in the radioisotope dilution assays for SAM measurement. Hence, its presence would lead to high estimates of SAM. The SAH bound to the anion exchange resin can be eluted from the column with $0.1 \mathrm{~N}$ $\mathrm{NaCl}$ (Shapiro and Ehninger, 1966) and measured separately using a modification of the same radioenzymatic assay that we have described (D. L. Wong, E. L. Zager, and R. D. Ciaranello, unpublished results).

Fxisting SAM assays have dealt with the problem of SAH contamination in samples in a variety of other ways: dual label radioenzymatic assay combined with mathematical analysis (Baldessarini and Kopin, 1966), single label radioenzymatic assay using radiolabeled SAM as an internal standard combined with mathematical analysis (Yu, 1978), or separation by thin layer or paper chromatography and measurement by absorption at $254 \mathrm{~nm}$ (Salvatore et al., 1971). The latter methodology, although appropriate to the separation procedure, is less sensitive than the enzymatic assays for SAM measurement. Even in the case of the two enzymatic assays, there was concern that the limits of the assays might obviate the detection of small tissue fluctuations in SAM. Although these protocols may account for SAH contamination, there is reason to believe that in vivo regulation may occur as a consequence of the relative proportions of SAM and SAH. Hence, a procedure was required which would separate SAM and SAH so that their concentrations could be determined independently. A method which separates and measures both SAM and SAH by reverse phase $\mathrm{C} 18$ high pressure liquid chromatography using gradient elution has appeared recently (Hoffman et al., 1979). However, this methodology requires the use of expensive equipment, is time consuming ( $80 \mathrm{~min} / \mathrm{run}$ ), and most importantly, requires gram quantities of tissue. Our procedure offers the advantage of being quick, simple, sensitive, and inexpensive.

This new procedure for SAM assay was used to test the possibility that SAM may regulate the intracellular proteolysis of PNMT and HIOMT. We have shown that both adrenal and pineal SAM levels decrease after hypophysectomy and are restored by dexamethasone administration. These results provide further evidence that glucocorticoids mediate the in vivo regulation of SAM in the adrenal and pineal and that SAM, in turn, regulates the in vivo degradation of both PNMT and HIOMT.

Perhaps even more interesting are our findings which suggest that hormonal control of SAM varies markedly in various regions of the brain and in peripheral tissues. In some peripheral tissues, and in some areas of the central nervous system, adrenal, pineal, striatum, and midbrain, SAM seems to be under glucocorticoid influence in that SAM levels decrease after hypophysectomy and are restored by dexamethasone administration. In other regions and tissues, thalamus, hypothalamus, hippocampus, and cerebellum, only a partial effect is observed or no effect at all. Although glucocorticoids may constitute one regulatory control of SAM, our results suggest that other controls exist as well. Some of these controls also may be endocrine factors. For example, in tissues where glucocorticoids are ineffective in reversing SAM changes in hypophysectomized animals, cortex, septum, pons-medulla, and liver, other pituitary factors may be important besides ACTH, the pituitary hormone responsible for glucocorticoid induction. Any of the pituitary hormones are possible candidates as these hormones are distributed both centrally and peripherally in other regions besides their classical target organ regions and are known to be involved in other non-target organrelated functions. In tissues where hypophysectomy and glucocorticoids are ineffective in altering SAM concentrations, the pituitary and its hormones probably are not involved in SAM regulation. However, control could occur centrally via the hypothalamic releasing hormones which have other biological activities in addition to the induction of the pituitary hormones.

Nonendocrine factors, particularly neuronal influences, also may regulate in vivo levels of SAM. Alternatively, a combination of hormonal and neuronal factors may be important.

This work emphasizes the multiplicity of factors involved in SAM regulation. Future work should concentrate on the further identification of the factors involved in SAM regulation. This should include an examination of other glucocorticoids, such as corticosterone, pituitary or hypothalamic hormones, and neural factors. In addition, it will be important to identify the biochemical sites

\section{TABLE VI}

Effect of hypophysectomy and dexamethasone on PNMT and MAT

Twelve animals were used per group. Hypophysectomized rats were administered dexamethasone phosphate daily for 1 week at a dose of 4 $\mathrm{mg} / \mathrm{kg}$ (i.p.). Animals were sacrificed, and the adrenals were removed. The tissue was homogenized in $0.03 \mathrm{M}$ potassium phosphate, $\mathrm{pH} 6.0$, $2.5 \mathrm{~mm}$ DTT. PNMT and MAT activities were measured simultaneously. PNMT was assayed as previously described. MAT was assayed by a modification of the procedure of Chou and Lombardini (1972).

\begin{tabular}{lcc}
\hline & PNMT Activity & MAT Activity \\
\hline & & units/pair \\
Control & $0.76 \pm 0.04$ & $0.0270 \pm 0.0020$ \\
Hypophysectomized & $0.03 \pm 0.01^{a}$ & $0.0025 \pm 0.0003^{a}$ \\
Hypophysectomized & $0.92 \pm 0.22^{b}$ & $0.0075 \pm 0.0013^{b}$ \\
$\quad$ + dexamethasone & &
\end{tabular}

"Significantly different from control at $p \leq 3 \times 10^{-8}$.

${ }^{b}$ Significantly different from hypophysectomized rats at $p \leq 10^{-3}$. 
of action on which these control systems are operant. Current studies are focusing on hormonal and nonhormonal regulation of methionine adenosyltransferase (MAT) and $S$-adenosylhomocysteine hydrolase, two enzymes involved in SAM metabolism. Preliminary evidence suggests that glucocorticoids regulate the levels of adrenal methionine adenosyltransferase, the enzyme responsible for SAM biosynthesis (Table VI).

\section{References}

Baldessarini, R., and I. J. Kopin (1966) SAM in brain and other tissues. J. Neurochem. 13: 769-777.

Berenbeim, D. M., D. L. Wong, S. J. Masover, and R. D. Ciaranello (1979) Regulation of synthesis and degradation of rat adrenal phenylethanolamine $N$-methyltransferase. III. Stabilization of PNMT against thermal and tryptic degradation by SAM. Mol. Pharmacol. 16: 482-490.

Cantoni, G. L. (1977) S-Adenosylmethionine: Present status and future perspectives. In The Biochemistry of S-Adenosyl. methionine, F. Salvatore, E. Borek, V. Zappia, H. G. Williams-Ashman, and F. Schlenk, eds., pp. 557-577, Columbia University Press, New York.

Chou, T. -C., and J. B. Lombardini (1972) A rapid assay procedure for ATP:L-methionine adenosyltransferase. Biochim. Biophys. Acta 276: 399-406.

Ciaranello, R. D. (1978) Regulation of phenylethanolamine $N$ methyltransferase synthesis and degradation. I. Regulation by rat adrenal glucocorticoids. Mol. Pharmacol. 14: 478-489.

Ciaranello, R. D., and I. B. Black (1971) Kinetics of the glucocorticoid-mediated induction of phenylethanolamine $\mathrm{N}$ methyltransferase in the hypophysectomized rat. Biochem. Pharmacol. 20: 3529-3530.

Deguchi, T., and J. D. Barchas (1971) Inhibition of transmeth- ylation of biogenic amines by $S$-adenosylhomocysteine. J. Biol. Chem. 246: 3175-3181.

Hoffman, D. R., W. E. Cornatzer, and J. A. Duerre (1979) Relationship between tissue levels of $S$-adenosylmethionine, $S$-adenosylhomocysteine, and transmethylation reactions. Can. J. Biochem. 57: 56-65.

Jackson, R. L., and W. J. Lovenberg (1971) The isolation and characterization of multiple forms of hydroxyindole $O$-methyltransferase. J. Biol. Chem. 246: 4280-4285.

Masover, S. J., D. M. Berenbeim, and R. D. Ciaranello (1979) Regulation of synthesis and degradation of rat adrenal phenylethanolamine $N$-methyltransferase. IV. Synergistic stabilization of the enzyme against thermal and tryptic degradation by SAM and biogenic amine substrates. Mol. Pharmacol. 16: 491-503.

McEwen, B. S. (1979) Influences of adrenocortical hormones. In Monographs in Endocrinology, J. D. Baxter and G. G. Rousseau, eds, pp. 467-492, Springer-Verlag, New York.

Moore, K. E., and O. T. Phillipson (1975) Effects of dexamethasone on phenylethanolamine $N$-methyltransferase and adrenaline in the brains and superior cervical ganglia of adult and neonatal rats. J. Neurochem. 25: 289-294.

Salvatore, F., R. Utili, and V. Zappia (1971) Quantitative analysis of $S$-adenosylmethionine and $S$-adenosylhomocysteine in animal tissues. Anal. Biochem. 41: 16-28.

Sandrock, A. W., Jr., G. G. Leblanc, D. L. Wong, and R. D. Ciaranello (1980) Regulation of rat pineal hydroxyindole $O$ methyltransferase: Evidence for SAM-mediated glucocorticoid control. J. Neurochem. 35: 536-543.

Shapiro, S. K., and D. J. Ehninger (1966) Methods for the analysis and preparation of SAM and $S$-adenosylhomocysteine. Anal. Biochem. 15: 323-333.

$\mathrm{Yu}, \mathrm{P}$. H. (1978) Radioenzymatic estimation of $S$-adenosylmethionine in rat brain regions and subcellular fractions. Anal Biochem. 86: 498-504. 